\title{
Wear Behavior of Commercial Tire Rubber against Mild Steel in Dry, Wet, and 3.5\% NaCl Corrosive Environment
}

\author{
Samiul Kaiser ${ }^{\mathrm{a}}$, Mohammad Salim Kaiser ${ }^{\mathrm{b}}$, Sheikh Reaz Ahmed ${ }^{\mathrm{c}}$ \\ ${ }^{a}$ Department of Civil Engineering \\ ${ }^{b}$ Directorate of Advisory, Extension and Research Services \\ 'Department of Mechanical Engineering \\ Bangladesh University of Engineering and Technology, Dhaka-1000, Bangladesh \\ Tel. No. 0088-02-9663129, Fax No. 0088-02-9665622, \\ e-mail: samiul.buet15@gmail.com
}

\begin{abstract}
The tribological performance of commercially used tire rubber was evaluated at ambient conditions under dry, wet, and 3.5\% NaCl corrosive environment. A pin-on-disc apparatus was used for the experiment. An applied load of $2.5 \mathrm{~N}$ at a sliding velocity of $0.246 \mathrm{~ms}^{-1}$ distance ranging from $75 \mathrm{~m}-2650 \mathrm{~m}$ were used for this study. The results showed that the nature of the wear rate was similar in all environments as initially increases afterward decreases to more or less a constant value. Moreover, the wear rate in the dry environment was significantly higher than that of the wet and corrosive environment. Water tends to lubricate the contact, reduce the heat generation as well as for sealing effects thus the wear rate is reduced. The coefficient of friction in wet and corrosive environments showed a lower value due to sealing and lubricating effect between the particles. The damage behaviors of worn surfaces were analyzed by optical microscope and SEM. At dry sliding conditions greater voids and holes are observed.
\end{abstract}

Keywords: Tire rubber; wear; friction; corrosion; SEM

\section{INTRODUCTION}

Tire wear is a complex observable fact. It depends on many parameters, like tire material and design, road conditions and surface characteristics, environmental conditions, and many others [1][1][3]. Rubber is a viscoelastic material, which means it has viscous and elastic properties after mechanical stress treatment. The elastic component is not time-dependent and creates a force that only depends on strain [4][5]. Frictional forces, such as, always oppose the motion or attempt it between objects in contact. Friction occurs in components because of the roughness of the surface in contact. In addition to environmental factors such as dry, wet, etc. and materials can also affect the wear behavior [6][7][8]. Rubber generates friction in three major ways: adhesion, deformation, and wear. Adhesion is a property of rubber that causes it to stick to other materials, as seen with adhesive tape. The rubber that rubs against the smooth surface generates the friction forces. Primarily, it is due to adhesion. It is different when the rubber rubs against a rough surface. The other mechanism, deformation, comes into play. In addition to adhesive friction and deformation friction, rubber produces traction forces by means of tearing and wear [9], [10].

Tire rubber used to move on various materials like concrete road, steel, sand, clay, etc. Sometimes it also moves through a different environment like a dry, wet, lubricant, salty water etc. The counter material and the environment play a great role in the wear behavior of the tire rubber. There are very few tribological experiments conducted on tire rubber against the mild steel under different environments. When a vehicle moves on the 
steel bridge or vessel near sea water, it has to face corrosive environment against mild steel counter body.

Tire wear up till now has many economic and ecological implications. The possibility to predict tire wear is therefore of major importance to tire manufacturers. There is therefore much to gain from an integrated approach to studying the mechanisms behind both wear phenomena. This paper discusses the evolution of wear behavior of commercial tire rubber in dry, wet, and $3.5 \% \mathrm{NaCl}$ corrosive environment against mild steel.

\section{Methods}

The frictional and wear behaviors were investigated in a pin-on-disc type wear apparatus by following ASTM Standard G99-05. The materials used in the current study were commercial tire rubber. The electrical muffle furnace was used for heating the tire rubber at various temperatures. The hardness of heated rubber samples at various states was measured in the Durometer Hardness tester. Differential scanning calorimetry (DSC) and thermo-gravimetric analysis (TGA) of the tire rubber were taken using DSC131 EVO and Thermo-Gravimetric Analyser, TGAQ50W respectively in a nitrogen environment. The samples for each measurement were maintained at $22.3 \mathrm{mg}$. DSC and TGA scans were performed at a heating rate of $10^{\circ} \mathrm{C} / \mathrm{min}$ from 30 to $600^{\circ} \mathrm{C}$. The sample of $12 \mathrm{~mm}$ length and $5 \mathrm{~mm}$ diameter were cut from the commercial tire rubber for wear study. Mild steel discs were used as the counter-body material. The hardness of the discs was RC 50. One of the surfaces of the disc was grinded by different grinding wheel to produce the different surface roughness. The surface roughness of the used discs was 35, 31, 27 and $13 \mu \mathrm{m}$. During the wear tests, the end surface of the pin samples was pressed against horizontal rotating mils steel disc. An applied load of $2.5 \mathrm{~N}$ was used throughout the test, which yielded nominal contact pressures of $0.13 \mathrm{MPa}$. The tests were conducted at the sliding speed of $0.246 \mathrm{~ms}^{-1}$ with varying sliding distances ranging from $75 \mathrm{~m}-2650 \mathrm{~m}$ and in ambient air (relative humidity72\%) under the dry sliding conditions (without lubrication). For wet and corrosive wear tests, distilled water and $3.5 \% \mathrm{NaCl}$ solution were used as the wet and corrosive medium respectively with all other parameters similar to dry wear test. A wet and corrosive immersion test was used where the MS disc and the wear samples were immersed in distilled water and a $3.5 \% \mathrm{NaCl}$ solution. At least three tests were done for each type of tire rubber. Wear rates were calculated from the average values of weight-loss measurements. Wear rate was estimated by measuring the weight loss $(\Delta W)$ after each test. Care has been given after each test to avoid entrapment of wear debris. The wear rate was calculated using the following expression [10]-

$$
W \cdot R=\frac{\Delta W}{S \cdot D \times L}
$$

Here,

$W . R=$ Wear Rate,$\quad \Delta W=$ Weight Loss

$S . D=$ Sliding Distance, $L=$ Load

Microstructural observation of the worn specimens was done using OPTIKA Microscope (Model: OPTIKA). The SEM investigation was conducted using a JEOL scanning electron microscope (Model: Link AN - 10000). Chemical composition and the physical and mechanical properties of tire rubber are given in Table 1 and Table 2 respectively.

Table 1. Chemical composition of the tire rubber (wt \%)

\begin{tabular}{cccccc}
\hline $\begin{array}{c}\text { Natural } \\
\text { Rubber }\end{array}$ & $\begin{array}{c}\text { Synthetic } \\
\text { Rubber }\end{array}$ & $\begin{array}{c}\text { Carbon } \\
\text { Black }\end{array}$ & Steel & $\begin{array}{c}\text { Zinc } \\
\text { oxide }\end{array}$ & $\begin{array}{c}\text { Fillers, } \\
\text { Extender oils }\end{array}$ \\
\hline 27 & 14 & 28 & $14-15$ & 2 & $16-17$ \\
\hline
\end{tabular}


Table 2. Physical and Mechanical Properties of the tire rubber

\begin{tabular}{cccc}
$\begin{array}{c}\text { Hardness, } \\
\mathbf{D H}\end{array}$ & $\begin{array}{c}\text { Density, } \\
\mathbf{K g} / \mathbf{m}^{3}\end{array}$ & $\begin{array}{c}\text { UTS, } \\
\mathbf{M P a}\end{array}$ & $\begin{array}{c}\text { Elongation, } \\
\%\end{array}$ \\
\hline 59 & 1217 & 7.2 & 180 \\
\hline
\end{tabular}

\section{RESULTS AND DISCUSSION}

\subsection{Hardness}

Figure 1 shows the material hardness of tire rubber under different temperatures. With the increase in temperature, the hardness of the material decreases. This is for the reason that rubber is an amorphous thermoplastic, in which the adjacent polymer chains associate through intermolecular forces, which weaken rapidly with increased temperature [12]. At the initial stage of temperature, the hardness drops sharply due to attain the glass transition point. The hardness is found to remain more or less stable over a range of temperatures around $60^{\circ} \sim 100^{\circ} \mathrm{C}$, which is realized to be associated with the rubbery state of the material. Finally, a drop of hardness is again observed because the rubber reaches near about its melting state.

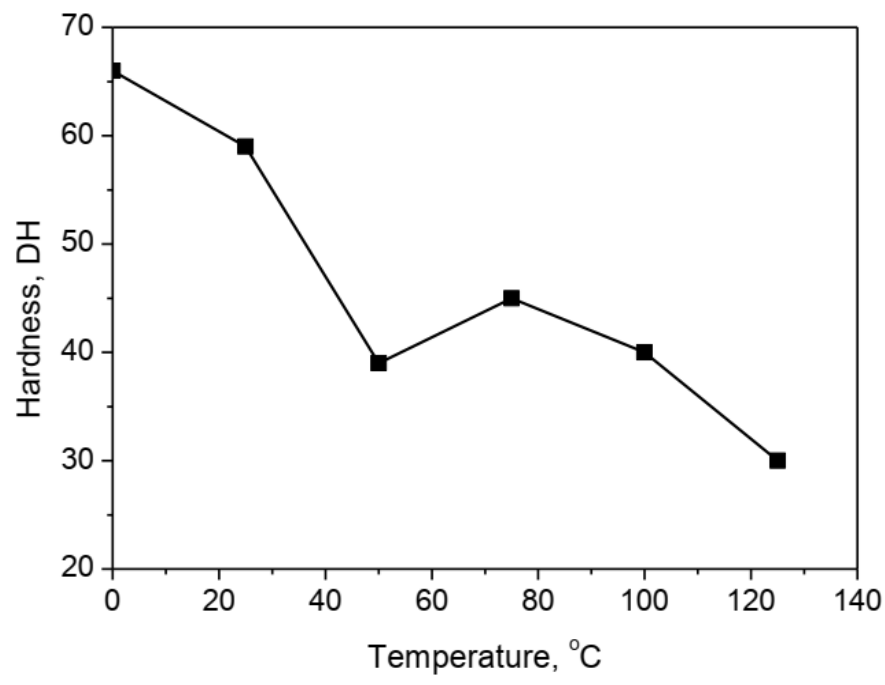

Figure 1. Variation of hardness with the temperature of the tire rubber

\subsection{DSC and TGA analysis}

The DSC and TGA analysis curves of tire rubber are given in Figure 2 to give up the information about the physical properties, kinetic analysis, and material stability as a function of temperature. It is noted from the DSC curve that an exothermic event observed in at $375^{\circ} \mathrm{C}$ is consistent with the polymer chains breaks in the vulcanization process. This is followed by the depolymerization of the compound, which coincides with the thermogravimetric results reported in the literature [13]. The TGA curve shows clearly that around $8 \%$ weight loss occurs between $50^{\circ} \mathrm{C}$ and $100^{\circ} \mathrm{C}$ indicating desorption of absorbed water. The $10 \%$ weight loss was recorded between $100^{\circ} \mathrm{C}$ and $350^{\circ} \mathrm{C}$ and this is due to $\mathrm{CO}_{2}$ desorption representing the decomposition of carboxyl, lactone and lactol groups. The $60 \%$ weight loss was recorded between $350^{\circ} \mathrm{C}$ and $600^{\circ} \mathrm{C}$ signifying $\mathrm{CO}$ desorption corresponding to the decomposition of carbonyl, ether, quinine and phenol groups on the carbon surface at higher temperatures. The result means that more $\mathrm{CO}$ was released from the decomposition process signifying the relative abundance of carbonyl and phenolic groups [14]. 


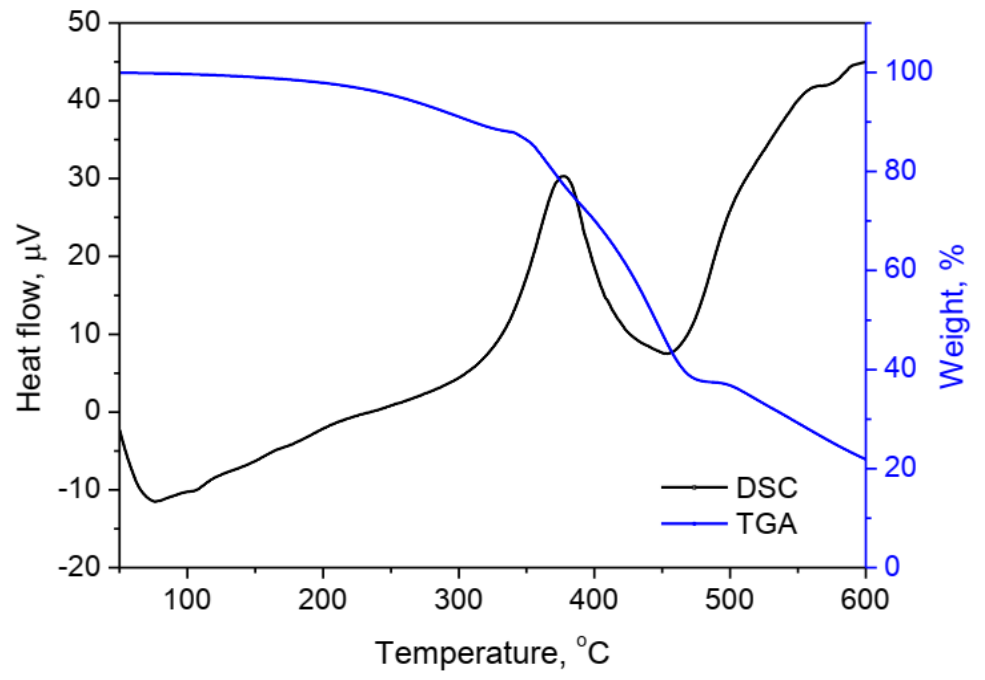

Figure 2. DSC and TGA curves of the tire rubber

\subsection{Wear study}

Figure 3 elucidates the variation of weight loss with sliding distance for tire rubber at an applied pressure of $0.13 \mathrm{MPa}$ in dry, wet and $3.5 \% \mathrm{NaCl}$ corrosive environment. It is shown that the weight loss naturally increases with the sliding distance for all environments. It is because of sliding distance increases, the contact between the rotating disk surface and the sliding surface of the specimen becomes more familiar with the elapse of time [15]. However, at the dry sliding condition the tire rubber shows higher weight loss than that of in the wet and corrosive environment. The reason that the temperature between the rotating disk surface and the sliding surface of specimen increases and leads to the softening of materials and plastic state of materials occurs.

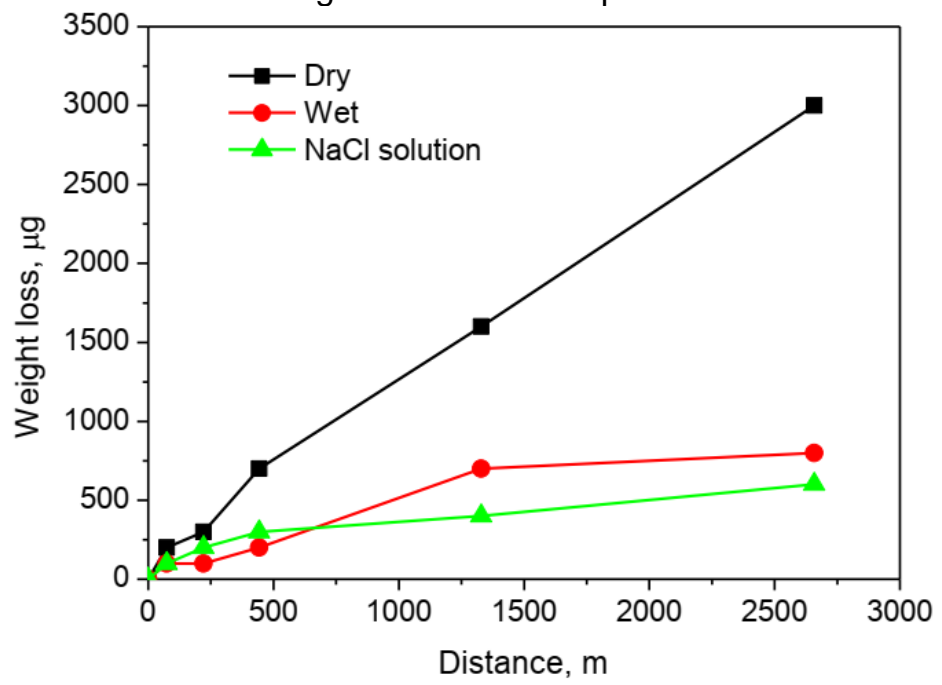

Figure 3. Variation of weight loss with sliding distance at an applied load of $2.5 \mathrm{~N}$ and sliding velocity $0.246 \mathrm{~ms}^{-1}$ in dry, wet and $3.5 \% \mathrm{NaCl}$ corrosive environment

Moreover, Figure 4 depicts the variation of wear rate with the variation of sliding distance in a different environment. The wear rate increases up to a certain point with sliding distance and afterward attains a plateau for all environments. However, the wear rate at the dry environment is higher than the other two wet and corrosive environments. This is mainly for the adhesive contribution results from the attractive binding forces between the rubber surface and the contact surface [16]. These interactions are often dominated by weak van der Waals force, as a result under dry condition frictional wear is large [17]. On a wet surface the water may partially or totally interrupt the contact 
between the tire rubber and the counter surface and that leads to a decrease of the friction, as a result surface friction is comparatively low therefore less wear rate. In salty water there are so many elements like chlorine, sodium, etc. These create a layer on the surface of the rubber, which reduces the wear rate of rubber under the salty wet surface [18].

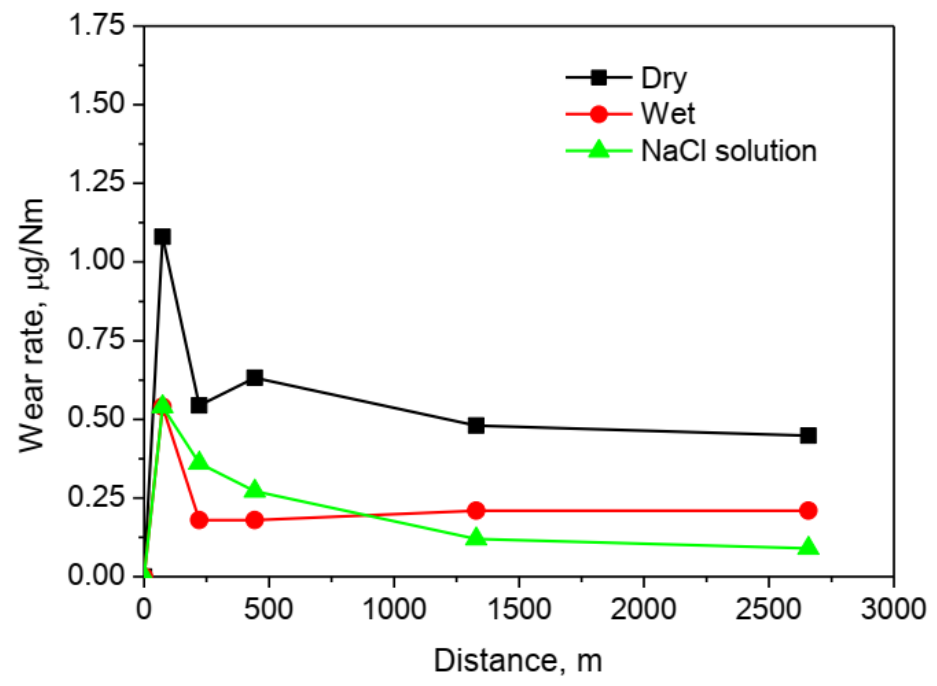

Figure 4. Variation of wear rate with sliding distance at an applied load of $2.5 \mathrm{~N}$ and sliding velocity $0.246 \mathrm{~ms}^{-1}$ in dry, wet and $3.5 \% \mathrm{NaCl}$ corrosive environment.

Figure 5 shows the variation of frictional coefficient with the sliding distance in dry, wet, and $3.5 \% \mathrm{NaCl}$ corrosive environment. The increase of the frictional coefficient for a dry environment is much greater than under wet and salty wet environments. Same sliding distance and loading condition frictional coefficient under wet surface drop from that of dry surface condition. When surfaces get wet, the roughness of the surfaces in contact drops substantially due to the sealing effect [19]. As a result frictional force between the contact surface and tire rubber reduces. When compare with wet and $3.5 \%$ $\mathrm{NaCl}$ corrosive environment, it can be seen that frictional force is higher in the corrosive environment because of its higher viscosity. The dissolved sodium chloride separates into sodium and chlorine atoms, and fill in the spaces between the water molecules. As a result the saltwater has a higher viscosity than freshwater [18].

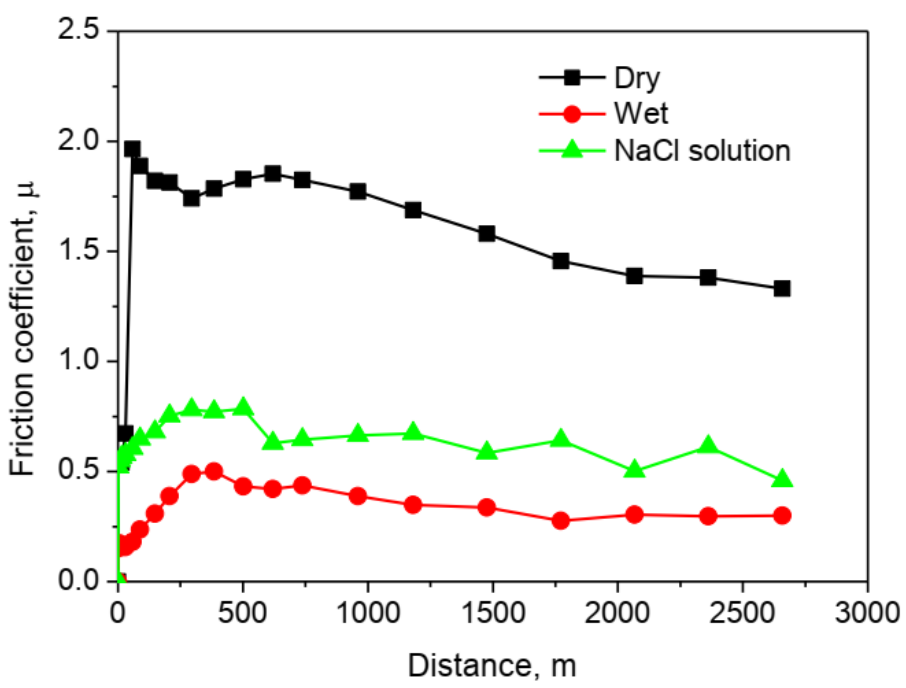

Figure 5. Variation of coefficient of friction with the sliding distance at applied load of $2.5 \mathrm{~N}$ and sliding velocity $0.246 \mathrm{~ms}^{-1}$ in dry, wet and $3.5 \% \mathrm{NaCl}$ corrosive environment. 
From the Figure 6, it is seen that the coefficient of friction increases with normal load in all environments. It is due to the fact that the contact area increases with normal load, as a result friction between tire rubber and contact surface increases. Some factors such as high plowing, surface damage and breakage of reinforced materials are also responsible for higher friction with higher normal load [20], [21]. Obviously in dry surface friction force is higher than two others. For dry environment as there is direct contact of tire rubber with a sliding surface so more friction occurs between the mating surface. Under heavy loading, there is also an effect of adhesion and for long sliding distance rubber stick with mating contact surface as a result greater frictional force occurs. On the other hand with an increasing normal load corresponding frictional force increases slightly in wet and salty wet surface conditions. The reasons behind this are sealing effect, slippage and others as discussed earlier. Again comparing with a normal wet surface, the salty wet surface has a slightly lower increase in frictional load, this is due to the generation of the layer above the rubber surface by elements of salt. Herewith the increase of normal load frictional coefficient of rubber initially increases but ultimately decreases after a certain range. Increased surface roughness and a large quantity of wear debris are believed to be responsible for the decrease in friction with the increase in normal load.

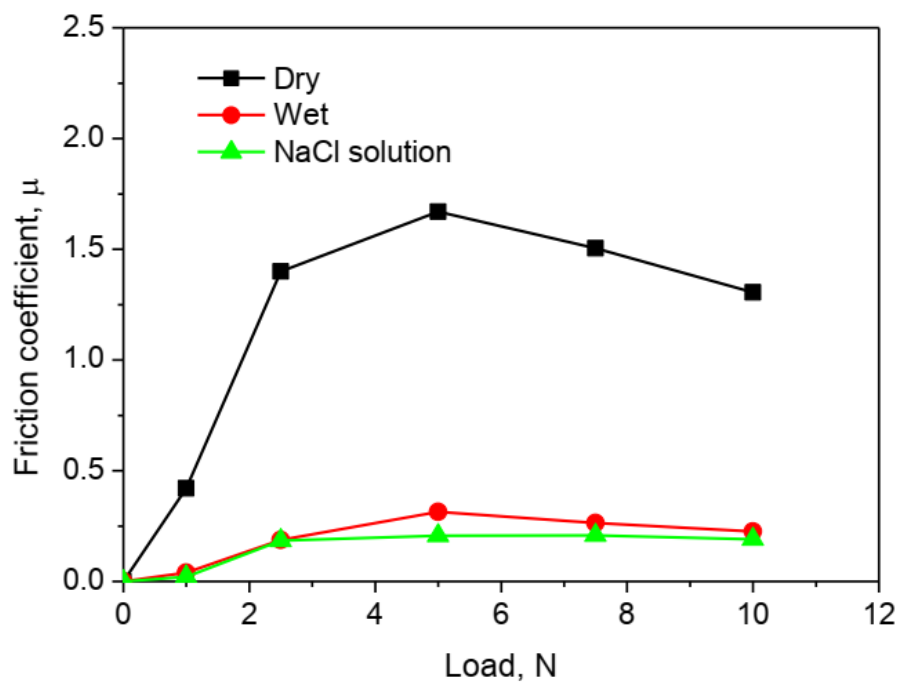

Figure 6. Variation of the coefficient of friction with applied load at a sliding velocity of $0.246 \mathrm{~ms}^{-1}$ in dry, wet and $3.5 \% \mathrm{NaCl}$ corrosive environment.

In

Figure 7, the low wear rate has low surface roughness. The rate of wear is less compared with the surface of the reason is attributed to increasing the surface roughness reduces the area of contact real are concentration load only in the areas of contact between the surfaces and gets broken layer oxide and cause an adhesion metal is strong and therefore, the force required to cut notches related to higher than the force required to cut the bonds of rubber. Wear of rubber, in general, referred to as abrasive wear even though the counter surface may not be an abrasive one. When the rubber surface is sliding against a rough surface under normal load then sliding contact generates shear stress along the rubber surface. Fracture initiates when this shear stress exceeds the cohesive strength of the rubber molecules which are curved, entangled or cross-linked in nature [22].

Figure 8 shows that the surface roughness increases the friction coefficient increase. In dry sliding wear of rubber, the primary wear mechanism is adhesive wear in which the worn surface layers adhere to the wear track. As wear increased at elevated temperatures, adhesion also increased. This resulted in roughness increment of the wear tracks, which, in turn, led to the coefficient increment of friction. A layer of surface film was formed on the surface of the rubber material in the dry sliding process due to the 
JEMMME (Journal of Energy, Mechanical, Material, and Manufacturing Engineering) Vol.5, No. 1, May 2020 | doi: $\underline{10.22219 / j e m m m e . v 5 i 1.10428}$

accumulation and compaction of transfer debris. The formation of this film could stable the friction coefficient and reduce the wear rate [23].

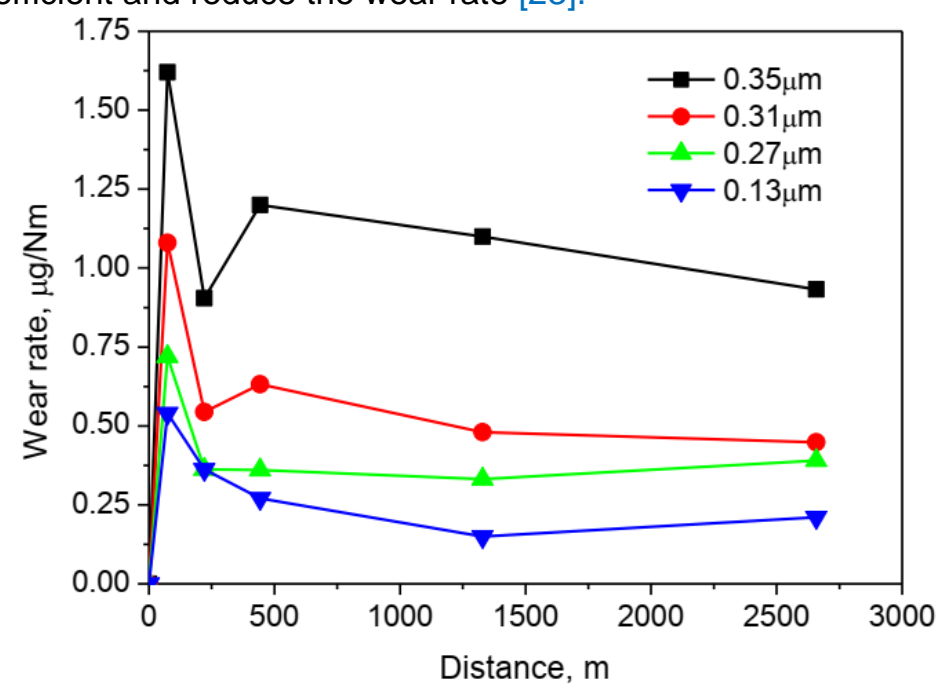

Figure 7. Variation of wear rate with sliding distance at different surface roughness applied load of $2.5 \mathrm{~N}$ and sliding velocity of $0.246 \mathrm{~ms}^{-1}$ in a dry environment.

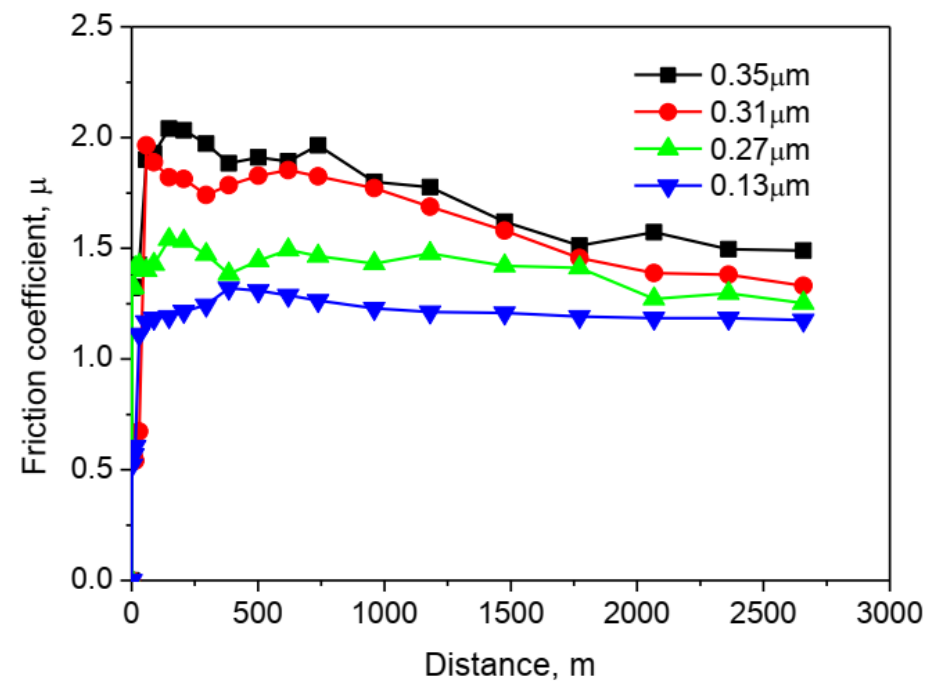

Figure 8. Variation of the coefficient of friction with sliding distance at different surface roughness applied load of $2.5 \mathrm{~N}$ and sliding velocity of $0.246 \mathrm{~ms}^{-1}$ in a dry environment.

\subsection{Optical microscopic observation}

Figure 9 is presented the worn surfaces for tire rubber before wear and after wear for 5 minutes in a different environment at $2.5 \mathrm{~N}$ load. Before wear test the worn surface display no indication of plastic deformation. The wear marks become visible on the worn surface after wear in dry sliding conditions. In some portions of the investigated worn surface there is evidence of crater formation. Generally, a transferred layer either in continuous or discontinuous form was observed for the samples. Whereas in the wet environment, the wear tracks displayed on the worn surface are smoother. The debris and grooves are observed only in limited regions. Besides, there are some areas seen due to the lubricating and cooling effects. The wear rate was low, due to the amount of metal removed being controlled to the thickness of this oxide formation. The heat concentration, local stress, and friction of shear decreased in the wet environment, thus inhibiting the generation of cracks and debris. The worn surface after wear at the corrosive environment was characterized by a surface with some corrosive layer. 
JEMMME (Journal of Energy, Mechanical, Material, and Manufacturing Engineering) Vol.5, No. 1, May 2020 | doi: 10.22219 /iemmme.v5i1.10428

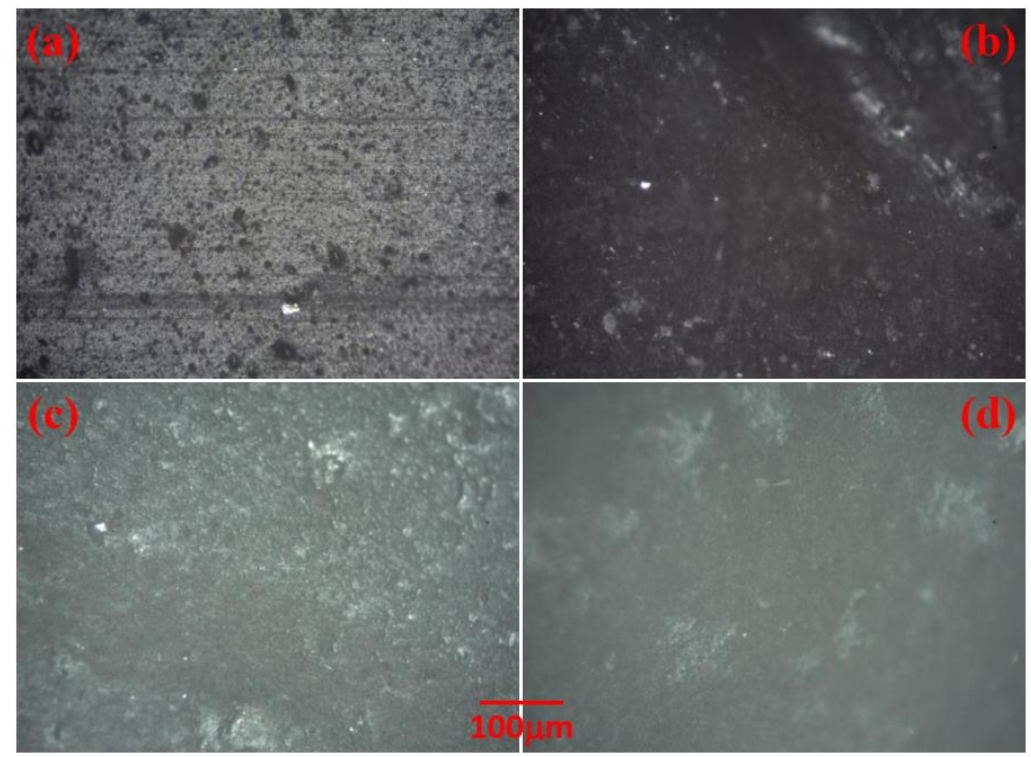

Figure 9. Optical micrograph of worn surfaces a) before wear, after wearing at an applied load of $2.5 \mathrm{~N}$ for $5 \mathrm{~min}$ in b) dry c) wet and d) $3.5 \% \mathrm{NaCl}$ corrosive environment

\subsection{SEM observation}

Figure 10a shows the SEM micrograph of the as-received structure of tire rubber with a moderately smooth surface and exhibits no symptom of plastic deformation or drawing. It was obvious that, the compressive bonding exhibits no void, hole or impurities, witnessing sound bonding ability of matrix and filler. As compared to after wearing for 180 min at dry environment Figure 10b shows voids and holes can be witnessed through the image, and if this continues, the formed micro holes could propagate into a crack to broadcast at a quicker rate. This clearly indicates that water absorbs heat that was generated at the specimen disc interface and also reduces friction to a greater extent, thus inhibiting the generation of cracks and debris.

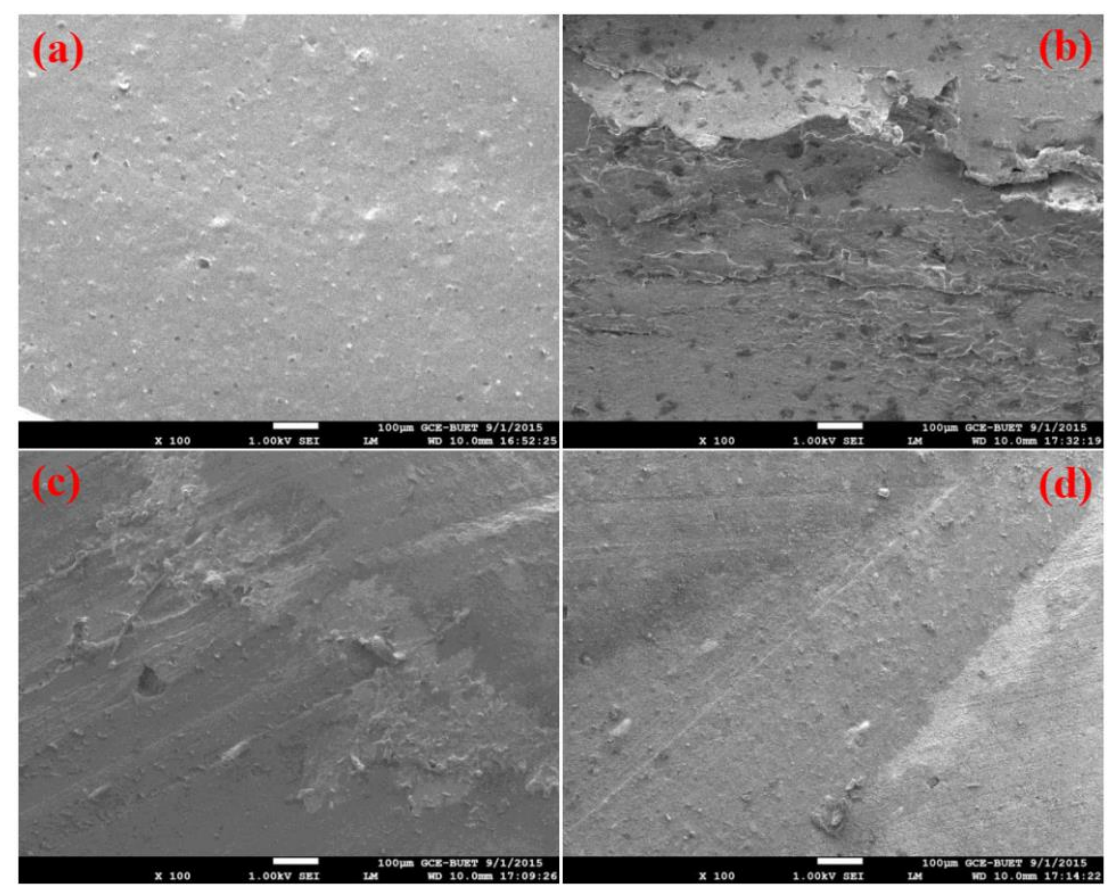

Figure 10. SEM micrographs of worn surfaces of tire rubber a) before wear, after wearing at an applied pressure of $0.13 \mathrm{MPa}$ for $180 \mathrm{~min} \mathrm{b)} \mathrm{dry} \mathrm{c)} \mathrm{wet} \mathrm{and} \mathrm{d)} 3.5 \% \mathrm{NaCl}$ corrosive environment. 
Hence, the amount of wear is very low in the case of the wet and corrosive sliding situation compared to the dry sliding situation. So the surface is relatively smooth as shown in Fig. 10c and 10d. [24]. In fact, the corrosion-wear occurred in the corrosive fluid, forming the oxidation film. Subsequently, the oxides were broken down and the wear debris was generated during the wear testing. Moreover, the friction heat was generated on the interface, leading to the formation of additional oxides. The crack and plastic deformation are not observed, and the size of debris and particles is smaller than that of the dry sliding condition.

\section{CONCLUSION}

The frictional wear is large for tire rubber under dry sliding condition is mainly for the adhesion and weak van der Waals force. In the wet environment, the roughness at the surface drops substantially for the sealing effect at the same time as wears loss decreases significantly from that of a dry environment. In a corrosive environment there are so many elements like chlorine, sodium, magnesium, etc. create a layer on the surface of rubber, which reduces the wear of rubber. The frictional coefficient under dry environment is much greater than under wet and salty wet environments. The reasons behind this are the sealing effect and slippage. As the normal loads increase in all environments frictional loads increase because of the increase of the contact area. Surface roughness also increases the friction coefficient and wear rate of tire rubber. In dry sliding wear of rubber, the voids and holes parallel to the sliding direction are shown on the worn surface in dry sliding condition whereas in a wet and corrosive environment, wear tracks displayed are smoother.

\section{ACKNOWLEDGMENTS}

This work is supported by the DAERS office of Bangladesh University of Engineering and Technology, Dhaka. Thanks to the Department of Glass and Ceramics Engineering for providing the laboratory facilities.

\section{REFERENCES}

1. Veith, A.G., "A review of important factors affecting tread wear", Rubber Chemistry and Technology. 1992; Vol. 65(3):601-658. https://doi.org/10.5254/1.3538631

2. Grosch, K.A., "Abrasion of rubber and its relation to tire wear", Rubber Chemistry and Technology. 1992; Vol. 65(1):78-106. https://doi.org/10.5254/1.3538609

3. Sueoka, A., Ryu, T., Kondou, T., Togashi, M., and Fujimoto, T., "Polygonal Wear of Automobile Tire", Trans. Jpn. Soc. Mech. Eng. 1997; Vol. 40(2):209-17. https://doi.org/10.1299/jsmec.40.209

4. Marvalova, B., "Viscoelastic properties of filled rubber experimental observations and material modeling", Engineering Mechanics. 2007; Vol. 14(1/2):81-89.

5. Chandran, V., Raj, T.M., Lakshmanan, T. and Kumar, M. S., "Influence of Different Fillers on Natural Rubber Composites to Assess Mechanical Performance", International Journal of Engineering, 2015; Vol. 28(6):932-939.

6. Lancaster, J.K., "A review of the influence of environmental humidity and water on friction, lubrication and wear", Tribology International, 1990; Vol. 23(6):371-389. https://doi.org/10.1016/0301-679X(90)90053-R

7. Jia, J.H, Zhou, H.D., Gao, S.Q., and Chen, J.M., "A comparative investigation of the friction and wear behavior of polyimide composites under dry sliding and waterlubricated condition", Materials Science and Engineering: A, 2003; Vol. 356(1-2):4853. https://doi.org/10.1016/S0921-5093(03)00052-2

8. Wang, A., Yan, S., Lin, B., Zhang, X., and Zhou, X., "Aqueous lubrication and surface microstructures of engineering polymer materials (PEEK and $\mathrm{PI}$ ) when sliding against $\mathrm{Si}_{3} \mathrm{~N}_{4}$ ", Friction, 2017; Vol. 5(4):414-428. https://doi.org/10.1007/s40544-017-0155-9

9. Barquins, M., "Adherence, friction and wear of rubber-like materials", Wear, 1992; Vol. 158 (1-2):87-117. https://doi.org/10.1016/0043-1648(92)90033-5

10. Heinrich, G., and Klueppel, M., "Rubber friction, tread deformation and tire traction", Wear, 2008; Vol. 265(7-8):1052-1060. https://doi.org/10.1016/i.wear.2008.02.016 
11. Kaiser, M.S., Sabbirb, S.H., Kabir, M.S., Rahman, M., and Nur, M.A., "Study of mechanical and wear behaviour of hyper-eutectic Al-Si automotive alloy through $\mathrm{Fe}$, $\mathrm{Ni}$ and $\mathrm{Cr}$ addition", Journal of Materials Research, 2018; Vol. 21(4):1-9. https://doi.org/10.1590/1980-5373-mr-2017-1096

12. Baeurle, S.A., Hotta, A., Gusev, A.A., "On the glassy state of multiphase and pure polymer materials”, $\quad$ Polymer, 2006; Vol. 47(17):6243-6253. https://doi.org/10.1016/j.polymer.2006.05.076

13. Ooi, Z.X., Ismail, H., Bakar, A.A., "Study on the ageing characteristics of oil palm ash reinforced natural rubber composites by introducing a liquid epoxidized natural rubber coating technique", Polymer Testing, 2014; Vol. 37:156-162. https://doi.org/10.1016/i.polymertesting.2014.05.003

14. Saleh, T.A., Danmaliki, G.I., "Adsorptive desulfurization of dibenzothiophene from fuels by rubber tyres-derived carbons: Kinetics and isotherms evaluation", Process Safety and Environmental Protection, 2016; Vol. 102:9-16. https://doi.org/10.1016/i.psep.2016.02.005

15. Hutchings, I.M., "Tribological properties of metal matrix composites", Materials Science and Technology, 1994; Vol. 10(6):513-517. https://doi.org/10.1179/mst.1994.10.6.513

16. Persson, B.N.J., Tartaglino, U., Albohr, O., and Tosatti, E., "Rubber friction on wet and dry road surfaces: The sealing effect", Physical review. B. Condensed matter, 2005; Vol. 71(3):1-8. https://doi.org/10.1103/PhysRevB.71.035428

17. Rimai, D.S., Ezenyilimba, M.C., and Quesnel, D.J., "Effects of electrostatic and van der Waals interactions on the adhesion of spherical $7 \mu \mathrm{m}$ particles", The Journal of Adhesion, 2005; Vol. 81(3-4):245-269. https://doi.org/10.1080/00218460590944549

18. Chen, S.F., Chan, R.C., Read, S.M., and Bromley, L.A., "Viscosity of sea water solutions", Desalination, 1973; Vol. 13(1):37-51. https://doi.org/10.1016/S00119164(00)80090-9

19. Meyer, W.E., and Walter, J.D., "Frictional Interaction of Tire and Pavement, American Society for Testing and Materials," Race Street, Philadelphia, USA, (1983). https://doi.org/10.1520/STP793-EB

20. Nuruzzaman, D.M., Chowdhury, M.A., and Rahaman, M.L., "Effect of Duration of Rubbing and Normal Load on Friction Coefficient for Polymer and Composite Materials", Industrial Lubrication and Tribology, 2011; Vol. 63(5):320-326. https://doi.org/10.1108/00368791111154931

21. Araji, N.A., and Sarhan, H., "Effect of Temperature on Sliding Wear Mechanism under Lubrication Conditions", International Journal of Engineering, 2011; Vol. 5(2):176-184.

22. Zappone, B., Rosenberg, K.J. and Israelachvili, J., "Role of nanometer roughness on the adhesion and friction of a rough polymer surface and a molecularly smooth mica surface", Tribology Letters, 2007; Vol. 26(3):191-201. https://doi.org/10.1007/s11249006-9172-y

23. Li, X.Y., and Tandon, K.N., "Microstructural characterization of mechanically mixed layer and wear debris in sliding wear of an Al alloy and an Al based composite", Wear, 2000; Vol. 245(1-2):148-161. https://doi.org/10.1016/S0043-1648(00)00475-0

24. Bharathi, V., Ramachandra, M., and Srinivas, S., "Comparison of Dry and Wet Sliding Wear Behavior of Squeeze Cast Aluminum Alloy", Indian Journal of Advances in Chemical Science, 2016; Vol. S1:101-106. 